\title{
Anatomic relationship of the coronary orifice and truncal valve in truncus arteriosus and their surgical implication
}

\author{
Ing-Sh Chiu, MD, PhD, MDiv, ${ }^{a}$ Shye-Jao Wu, MD, ${ }^{a}$ Ming-Ren Chen, MD, ${ }^{b}$ Shyh-Jye Chen, MD, ${ }^{c}$ and \\ Jou-Kou Wang, MD, ' Taipei, Taiwan
}

1 trileaflet configuration is considered essential to maintaining the competence of a chorda-less semilunar valve. ${ }^{1}$ Bicuspid aortic and pulmonary valves are prone to stenosis, and quadricuspid valves are susceptible to regurgitation. Truncal insufficiency occurs more frequently in quadricuspid than tricuspid valves, but no cases have occurred in bicuspid valves. ${ }^{2}$ One method of restoring competence in truncal insufficiency is to excise one of the quadricuspid truncal valves (QTV) with its wall. ${ }^{2}$ To use that supernumerary cusp and its truncal wall, we reviewed the reported truncal valve anatomy in relation to the coronary orifice and conceived the following procedure for reconstruction.

\section{Review}

We analyzed the relationship of the coronary orifice to the truncal valve in persistent truncus arteriosus. A total of 301 cases were reported with a diagram showing the relationship of the coronary orifice to the truncal valve. ${ }^{3-9}$ Four cases with unequal cusp size on the diagram were excluded from analysis. The coronary information of one case with a pentacuspid valve was not available. In the other 296 cases, the coronary orifice was depicted (Figure 1) according to various truncal rotations. A pulmonary cusp was present in all 194 cases that had QTV (Figure 1). The pulmonary cusp was located at the anterior portion of the truncal root in the vast majority $(92.2 \%, 59 / 64$; right anterior, $26.6 \%$; directly anterior, $34.3 \%$; left anterior, $31.3 \%)$; the rest $(7.8 \%, 5 / 64)$ were in the left lateral portion. For those with a tricuspid $(\mathrm{n}=194)$ or bicuspid $(\mathrm{n}$ $=38$ ) truncal valve, the facing commissure was still directed

From the Departments of Surgery, ${ }^{\mathrm{a}}$ Medical Imaging, ${ }^{\mathrm{c}}$ and Pediatrics, ${ }^{\mathrm{d}}$ National Taiwan University Hospital, and the Department of Pediatrics, ${ }^{\mathrm{b}}$ Mackay Memorial Hospital, Taipei, Taiwan.

This study was supported by a grant from the National Science Council NSC90-2314-B002-419.

Received for publication July 12, 2001; accepted for publication Aug 15, 2001.

Address for reprints: Ing-Sh Chiu, MD, Department of Surgery, National Taiwan University Hospital, No. 7 Chung-Shan S. Rd, Taipei, Taiwan 100 (Email: ingsh@ha.mc.ntu.edu.tw).

J Thorac Cardiovasc Surg 2002;123:350-2

Copyright (C) 2002 by The American Association for Thoracic Surgery

$0022-5223 / 2002 \$ 35.00+0 \quad \mathbf{1 2 / 5 4 / 1 1 9 6 9 2}$

doi:10.1067/mtc. 2002.119692 toward the site where the pulmonary trunk root (circle in Figure 1) would have been had it been formed in persistent truncus arteriosus. The coronary artery penetrated the facing sinus in the tricuspid group in the majority $(63.4 \%, 123 / 194)$. The artery might penetrate the nonfacing sinus in $71(37 \%)$ of 194 tricuspid valves, and it did penetrate the sinus in $6(9 \%)$ of 64 cases of QTV. In 1 case of QTV, the right coronary artery penetrated the right anterior pulmonary sinus, ${ }^{5}$ and in the other case it penetrated above the commissure between the right coronary and pulmonary cusps. ${ }^{6}$

In total, the unformed pulmonary trunk root was in the right anterior portion in $14.2 \%$, directly anterior in $50.0 \%$, left anterior in $30.1 \%$, and left lateral in $5.7 \%$ of 296 cases. Although the pulmonary trunk or artery is supposed to arise from this assumed circle in Figure 1, this categorization is of surgical significance, as described below.

\section{Clinical Summary}

A 3-day-old baby boy weighing $2.4 \mathrm{~kg}$, who had DiGeorge syndrome, was admitted to the hospital because of a heart murmur noted after birth and cyanosis during milk feeding. Findings of echocardiography and cardiac catheterization showed type 1 persistent truncus arteriosus, QTV with moderate truncal insufficiency, a large ventricular septal defect (VSD), and hypoplastic left and right pulmonary arteries. Low pulmonary artery pressure (17/7 $\mathrm{mm} \mathrm{Hg}$ ) and systemic arterial oxygen saturation (87\%) were found by cardiac catheterization. Electron beam computed tomographic scans indicated that the pulmonary trunk arose from above the pulmonary cusp of the QTV.

Surgical correction was performed when he was 1 month old. An arterial duct was closed just before instituting cardiopulmonary bypass. A transverse truncotomy was done first and then vertical extension (Figure 2, A) to ascertain a QTV with juxtacommissural coronary orifices (inset). An instrument was passed into the truncal root to probe the planned site of ventriculotomy. After oblique ventriculotomy (Figure 2, B), the truncal anulus was cut open between the right coronary and pulmonary cusps from above, along with the outlet septum below it, until the cephalic margin of the VSD was enlarged by anterior cutback. The truncal wall above the pulmonary cusp was everted to the left (Figure 2, B, inset). The pulmonary orifice in the truncal wall and the pulmonary trunk were opened near the right side (Figure 2, $C$ ). The rudimentary pulmonary cusp was excised and a new commissure created (inset). The neoaorta was reconstructed by suturing the flap (marked \# in Figure 1) directly to the intimal side of the truncus to exclude the pulmonary orifice. Through the VSD, aortic regurgitation was not found on infusion of cardioplegic solution. The VSD and outlet septum, which had been 


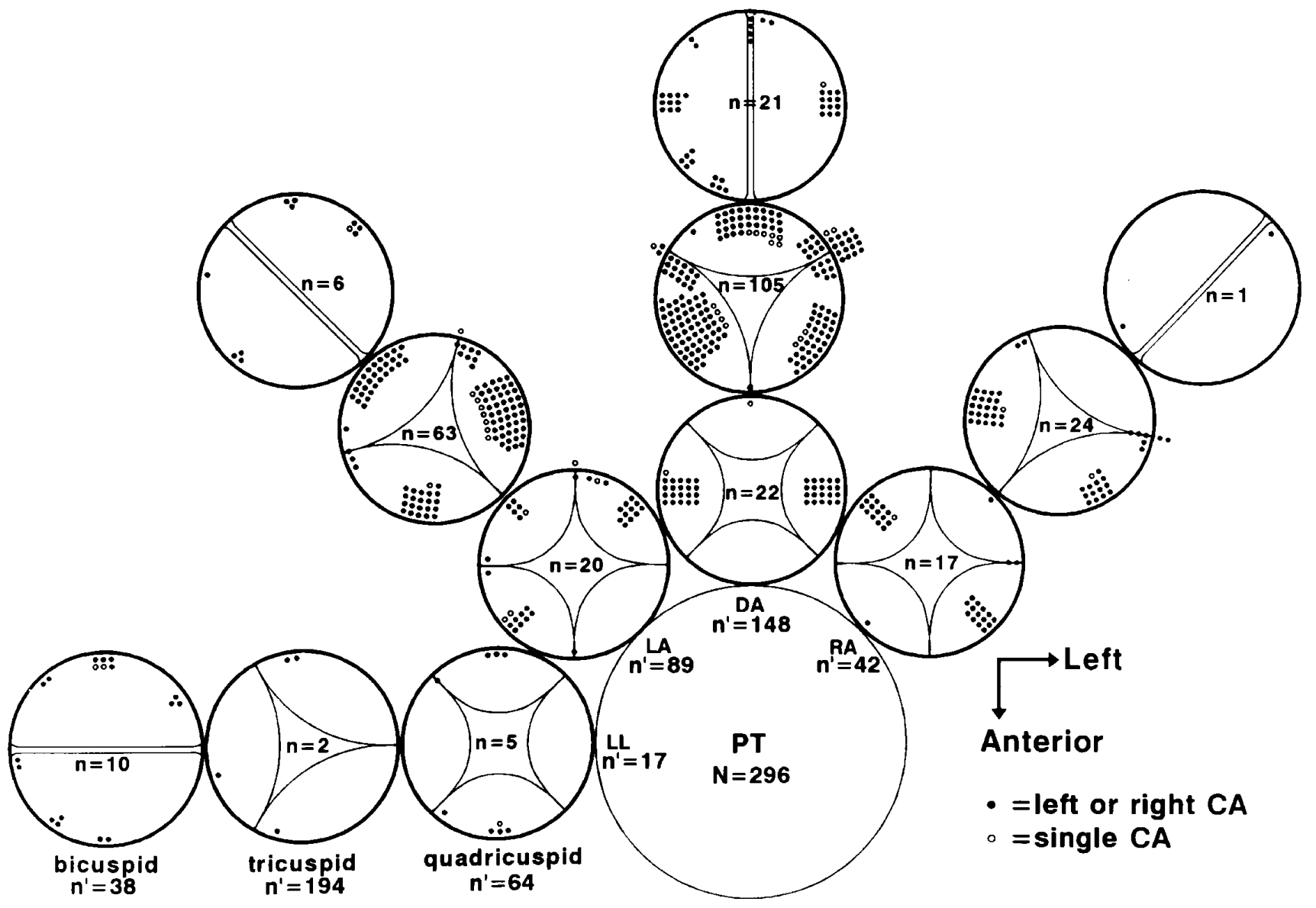

Figure 1. Relationship of the coronary orifice to the truncal valve according to various truncal rotations. The facing commissure of a bicuspid or tricuspid valve is still directed toward the supposed pulmonary trunk in the center that is not formed in a persistent truncus arteriosus. A pulmonary cusp was present in all cases of quadricuspid valve. The coronary artery may penetrate the nonfacing sinus in $9 \%$ of quadricuspid and $37 \%$ of tricuspid valves, yet the majority of coronary penetrations into the facing sinus can indicate the site of pulmonary reconstruction to be created in repair. $C A$, Coronary artery; $D A$, directly anterior; $L A$, left anterior; $L L$, left lateral; $P T$, pulmonary trunk; $R A$, right anterior.

cut open, were then closed in one Dacron patch. The caudal edge of the everted flap (Figure 2, $A^{\prime}$ ) and also that of the pulmonary trunk $(P)$, which had been cut open, were sutured to the cephalic margin of the ventriculotomy (Figure 2, D) to reconstruct the posterior pulmonary pathway. The right edge of the pulmonary trunk $(P)$ was attached to the left edge of the everted truncal flap above the open pulmonary orifice. Finally, the anterior portion of the pulmonary pathway was roofed with fresh pericardium $\left(P^{\prime}\right.$, depicted by a transparent patch) along the shallow dashed line. A common wall $(A)$ was thus shared between the neoaorta and the pulmonary pathway. Aortic crossclamp time was 114 minutes and bypass time was 210 minutes.

The patient was separated from cardiopulmonary bypass without significant difficulty. At intraoperative transesophageal echocardiography, there was only trivial aortic regurgitation, no residual VSD, and a patent right ventricular outflow tract. The patient was transferred to the intensive care unit with the sternum open because of myocardial swelling. The patient recovered grad- ually. The sternum was closed 5 days after surgery, and the patient was gradually weaned from the ventilator. Unfortunately, an unwitnessed cardiac arrest occurred after removal of the endotracheal tube. The patient recovered hemodynamically after reintubation but had hypoxic encephalopathy.

\section{Discussion}

Van Praagh and Van Praagh ${ }^{10}$ proposed the concept of the pulmonary cusp in persistent truncus arteriosus that might obstruct the pulmonary orifice-namely, location of the pulmonary arteries or trunk above the pulmonary cusp. This finding is consistent with our review that a pulmonary cusp was present in all 64 cases of QTV (Figure 1). The pulmonary trunk or its branch is supposed to arise from above this cusp. It had also been reported that a small area on the left lateral truncal circumference $\left(>325^{\circ},<25^{\circ}\right)$ was devoid of coronary orifices. ${ }^{11}$ This part of the truncal wall and its cusp can therefore be used as described. However, in rare cases in which the coronary orifice is present in the anterior pulmonary sinus or its 

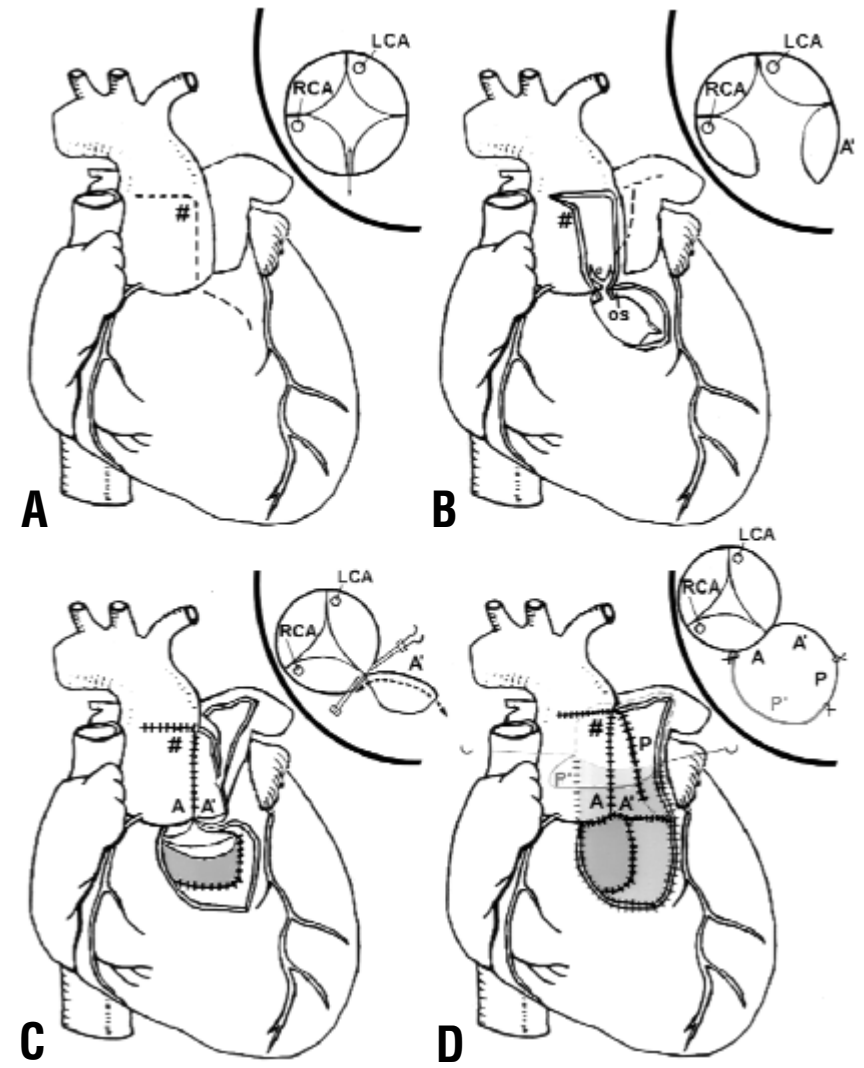

Figure 2. Operative technique of concomitant truncal valve repair and pulmonary artery reconstruction. Please refer to the text for details. $A$, Aorta; $A^{\prime}$, everted truncal wall; $L C A$, left coronary artery; os, outlet septum; $P$, pulmonary trunk; $P^{\prime}$, pericardium; $R C A$, right coronary artery; \#, flap.

commissure (Figure 1), we would recommend coronary transfer if our method was being used. One should reconstruct the coronary artery in persistent truncus arteriosus if necessary, especially in the presence of ostial stenosis, tangential origin, intramural course with juxtacommissural origin or high takeoff, and acute angle takeoff. ${ }^{4}$ If the pulmonary cusp is rudimentary, a valveless reconstruction with an autologous pedicle flap could be done by this common wall technique, even with a bicuspid or tricuspid truncal valve with adequate truncal wall adjacent to the pulmonary orifice or a type 2 persistent truncus arteriosus. Because the coronary artery usually penetrated the facing part of the great arteries (Figure 1), one could use it to define the facing commissure and thus assume the site of neo- pulmonary trunk reconstruction for persistent truncus arteriosus with bicuspid or tricuspid truncal valve. The new coronary categorization in persistent truncus arteriosus according to the aortopulmonary (truncal) rotation is similar to the previous classifications in complete transposition ${ }^{12}$ and tetralogy of Fallot ${ }^{13}$; this has surgical implications as described above.

We believe pedicle flap reconstruction of the pulmonary pathway is most suitable to repair persistent truncus arteriosus and tricuspidization for truncal insufficiency.

We are indebted to Misses Chang-Ying Lin and Ju-Hsiu Cheng for secretarial assistance.

\section{References}

1. Chiu IS, Chao SF, Wu MH, Wang JK, How SW, Hung CR, et al. Reconstruction of right ventricular outflow tract by autologous pericardial tri-semilunar valve with sinus of Valsalva: report of a case with absent pulmonary valve. J Formos Med Assoc. 1989;88:718-21.

2. Imamura M, Drummond-Webb JJ, Sarris GE, Mee RB. Improving early and intermediate results of truncus arteriosus repair: a new technique of truncal valve repair. Ann Thorac Surg. 1999;67:1142-6.

3. Shrivastava S, Edwards JE. Coronary arterial origin in persistent truncus arteriosus. Circulation. 1977;55:551-4.

4. Barbero-Marcial ML, Tanamati C. Repair of truncus arteriosus. Adv Card Surg. 1998;10:43-73.

5. Crupi G, Macartney FJ, Anderson RH. Persistent truncus arteriosus: a study of 66 autopsy cases with special reference to definition and morphogenesis. Am J Cardiol. 1977;40:569-78.

6. Suzuki A, Ho SY, Anderson RH, Deanfield JE. Coronary arterial and sinusal anatomy in hearts with a common arterial trunk. Ann Thorac Surg. 1989;48:792-7.

7. de la Cruz MV, Cayre R, Angelini P, Noriega-Ramos N, Sadowinski S. Coronary arteries in truncus arteriosus. Am J Cardiol. 1990;66: 1482-6.

8. Lenox CC, Debich DE, Zuberbuhler JR. The role of coronary artery abnormalities in the prognosis of truncus arteriosus. $J$ Thorac Cardiovasc Surg. 1992;104:1728-42.

9. Anderson KR, McGoon DC, Lie JT. Surgical significance of the coronary arterial anatomy in truncus arteriosus communis. Am J Cardiol. 1978;41:76-81.

10. Van Praagh R, Van Praagh S. The anatomy of common aorticopulmonary trunk (truncus arteriosus communis) and its embryologic implications: a study of 57 necropsy cases. Am J Cardiol. 1965;16: 406-25.

11. Bogers AJ, Bartelings MM, Bokenkamp R, Stijnen T, van Suylen RJ, Poelmann RE, et al. Common arterial trunk, uncommon coronary arterial anatomy. J Thorac Cardiovasc Surg. 1993;106:1133-7.

12. Chiu IS, Chu SH, Wang JK, Wu MH, Chen MR, Cheng CF, et al. Evolution of coronary artery pattern according to short-axis aortopulmonary rotation: a new categorization for complete transposition of the great arteries. J Am Coll Cardiol. 1995;26:250-8.

13. Chiu IS, Wu CS, Wang JK, Wu MH, Chu SH, Hung CR, et al. Influence of aortopulmonary rotation on the anomalous coronary artery pattern in tetralogy of Fallot. Am J Cardiol. 2000;85:780-4. 